ORIGINAL ARTICLE

\title{
Traffic calming policy can reduce inequalities in child pedestrian injuries: database study
}

\author{
S J Jones, R A Lyons, A John, S R Palmer
}

Injury Prevention 2005;11:152-156. doi: 10.1136/ip.2004.007252

\begin{abstract}
Objectives: To determine whether area wide traffic calming distribution reflects known inequalities in child pedestrian injury rates. To determine whether traffic calming is associated with changes in childhood pedestrian injury rates.

Design: Small area ecological study, longitudinal analysis of injury rates with cross sectional analysis of traffic calming and method of travel to school.

Settings: Two cities in the United Kingdom.

Participants: 4-16 year old children between 1992 and 2000.

Main outcome measures: Area wide traffic calming distribution by area deprivation status and changes in injury rate/ 1000 .

Results: The most deprived fourth of city $A$ had 4.8 times $(95 \% \mathrm{Cl} 3.71$ to 6.22$)$ the number of traffic calming features per 1000 population compared with the most affluent fourth. Injury rates among the most deprived dropped from 9.42 to 5.07 from $1992-94$ to $1998-2000$ (95\% Cl for change 2.82 to 5.91 ). In city $\mathrm{B}$, the traffic calming ratio of the most to least deprived fourth was 1.88 (95\% $\mathrm{Cl} 1.46$ to 2.42 ); injury rates in the deprived areas dropped from 8.92 to 7.46 (95\% Cl for change -0.84 to 3.77 ). Similar proportions of 9-12 year olds walked to school in both cities.

Conclusions: Area wide traffic calming is associated with absolute reductions in child pedestrian injury rates and reductions in relative inequalities in child pedestrian injury rates.
\end{abstract}

See end of article for authors' affiliations

Correspondence to:

Professor R Lyons,

University of Wales

Swansea, Swansed

Clinical School, Grove

Building, Singleton Park,

Swansea SA2 8PP, UK;

r.a.lyons@swansea.ac.uk

Accepted

22 December 2004
$\mathrm{P}$ edestrian injury is a leading cause of death and disability in children. ${ }^{-3}$ It is a major cause of health inequalities, with children from the most deprived areas at 4-5 times greater risk of involvement in a pedestrian road traffic accident than more affluent children. ${ }^{4-8}$ Substantial increases in injury rates are predicted over the next decade and these are expected to lead to further widening of the pedestrian injury rate inequalities gap. ${ }^{4}$

The success of different interventions has been variable and few have specifically targeted inequalities. ${ }^{9}$ Traffic calming aims to reduce traffic speed and volumes and therefore road traffic related injuries. The term can refer to approaches varying from speed humps to painted road sections, but the features most widely recognised as "traffic calming", particularly in the UK, are positive physical controls (speed humps, road narrowings, road closures, and speed cushions).

There have been few studies of the effectiveness of traffic calming. A systematic review of child and adolescent injury prevention concluded that traffic calming in 200 small areas contributed to a $70 \%$ decrease in child pedestrian injuries and a $9 \mathrm{mph}$ decrease in vehicle speeds. ${ }^{10}{ }^{11}$ In Denmark, road engineering measures contributed to a $15 \%$ decrease in injuries. ${ }^{12}$ A systematic review of area wide traffic calming identified only 16 controlled before and after trials, with the pooled rate ratio reduced for all deaths $(0.63)$, all injuries (0.89), but not for pedestrian injuries (1.0). ${ }^{13}$

Government policies focus increasingly on reducing health inequalities, but no study has looked at traffic calming distribution relative to known child pedestrian injury rate inequalities; there is no analysis of the effects of traffic calming on the inequalities gap. Logically, traffic calming should be located in areas where injury rates were historically high and, given known inequalities, these would probably be the most deprived areas. In the UK, provision of road engineering and road safety measures is the remit of the local authority. Decisions on where to locate calming will be influenced by road design, collision history, local support or opposition, and the views of local politicians.

This study aimed to compare the traffic calming distribution, by deprivation fourth, in two UK cities and to analyse how injury rates and inequalities for 4-16 year old pedestrians may have been affected by area-wide traffic calming.

\section{METHODS \\ Subjects}

Previous research has used various definitions of the "child". Here, the 4-16 year old population is studied because these are the ages of compulsory education in the UK. Preschoolers are involved in road traffic crashes, but exposure to the road traffic environment is low and injury events relatively few. After the age of 16, exposures increase to include use of the road traffic environment as drivers.

\section{Setting}

This study focussed on two UK cities, 45 miles apart, with similar total populations (250-300 000) and similar 4-16 year old populations (35-50 000). Each city consists of census tracts commonly referred to as electoral divisions (EDivs-average population 3000). Townsend Index of Material Deprivation scores, considered the best area based indicator of material deprivation available in the UK, ${ }^{15}$ are available for each EDiv. Nationally, all EDivs were assigned to a deprivation fourth based on Townsend scores. EDivs in the study cities were assigned to the appropriate fourth based on the national classification. In city A, $42.9 \%$ of EDivs were in the most deprived fourth (Townsend range 3.0-9.7), compared with $23.8 \%$ in city B (Townsend range $2.3-11.3$ ).

Electoral division boundaries are regularly changed. All data were fitted to the 1998 EDiv boundaries. Analyses were based on deprivation fourths because too few events occur in each individual EDiv. 
Table 1 Distribution of traffic calming features by deprivation fourth, rate ratios (rates calculated per 1000 4-16 year olds) and confidence intervals for the rate ratio

\begin{tabular}{|c|c|c|c|c|c|c|}
\hline \multirow[b]{2}{*}{ All Wales fourth } & \multicolumn{3}{|c|}{ City A } & \multicolumn{3}{|l|}{ City B } \\
\hline & EDivs & $\begin{array}{l}\text { Traffic } \\
\text { calming } \\
\text { features (\%) }\end{array}$ & Rate ratio & EDivs & $\begin{array}{l}\text { Traffic } \\
\text { calming } \\
\text { features (\%) }\end{array}$ & Rate ratio \\
\hline Most affluent & 9 & $64(7.2)$ & 1.00 & 14 & 80 (14.5) & 1.00 \\
\hline Next affluent & 2 & $50(5.6)$ & $2.37(1.63$ to 3.44$)$ & 12 & $79(14.3)$ & 0.86 (0.63 to 1.18 ) \\
\hline Next deprived & 5 & $142(15.9)$ & $2.39(1.78$ to 3.21$)$ & 6 & $127(23.0)$ & $1.07(0.80$ to 1.41$)$ \\
\hline Most deprived & 12 & 635 (71.3) & 4.80 (3.71 to 6.22$)$ & 10 & $267(48.2)$ & 1.88 (1.46 to 2.42$)$ \\
\hline Total & 28 & 891 & & 42 & 553 & \\
\hline
\end{tabular}

\section{Traffic calming audit}

A street by street audit of traffic calming was carried out during April and May 2002 in both cities. Traffic calming features audited were speed humps, road narrowings, and road closures. Twelve figure grid references were obtained using global positioning systems (GPS) and plotted using ArcView 3.2. ${ }^{14}$

Initially it was intended that traffic calming feature installation dates would be used in a before and after approach. However, local authorities do not store these data in a readily available manner. Also, traffic calming has been installed on different roads in the same EDiv over a period of months or years, precluding simple time series analyses. Installation was mainly from the mid 1990s onwards; we therefore used three year periods from 1992 to 2000.

\section{Pedestrian casualties}

Injurious road traffic accidents, recorded by the police STATS 19 form, were accessed through the UK data archive. ${ }^{16}$ Child pedestrian casualty locations in both cities for the entire study period were mapped to EDivs and deprivation fourths. Three year data aggregations were used to generate sufficient cases to improve precision of estimates. ${ }^{17}$

\section{Population denominators}

The 4-16 year old population of each EDiv and fourth was calculated using an extract from the NHS Administrative Register. ${ }^{8}$ To account for population changes, 1991 census data were aggregated to 1998 EDiv boundaries and population denominators for 1993 (denominator for 1992-94) and 1996 (denominator for 1995-97) estimated. For 1998-2000 the 1999 NHSAR population estimate was the denominator.

\section{Analysis of traffic calming and injuries data}

Traffic calming "rates" were calculated using the 1999 4-16 year population as a denominator and number of calming features as numerator. Traffic calming "rate" ratios were calculated for each fourth against the most affluent. ${ }^{18}$
Child pedestrian injury rates were calculated using the STATS19 numerator and population denominators. Changes in injury rates between 1992-94 and 1998-2000 were calculated, with $95 \%$ confidence intervals. ${ }^{19}$ Injury rate ratios, against the most affluent, were calculated for each fourth. ${ }^{18}$

\section{Potential confounders}

To account for possible confounding data on school travel mode was sought. Few appropriate exposure data were already available, but the road safety department of city A was independently conducting a school travel survey. We conducted a similar survey in city B. A single sheet survey was used, with pupils aged 9-12 years asked about modes of travel on that day. The proportions of children travelling to school by each mode and deprivation fourth were calculated. Car ownership data were obtained from the 1991 and 2001 census.

The total lengths of all roads, by fourth, were calculated using Meridian 2 software. ${ }^{20}$ Total road length, average distance between features, and feature density (features per unit road length) were calculated.

\section{RESULTS}

\section{Traffic calming}

There were 891 traffic calming features in city A, mainly in the most deprived fourth (71.3\%; table 1). City B had 553 features, with $48.3 \%$ in the most deprived fourth. There were 4.8 times more features in the most deprived compared with most affluent fourth of City A (table 1).

\section{Road network}

Features in city A were closer than city B for all except the most affluent (table 2).

Features were eight times further apart in the most affluent areas, compared with the most deprived in city A. In city $\mathrm{B}$ the ratio was 4.2 .

\begin{tabular}{|c|c|c|c|c|c|c|}
\hline \multirow[b]{2}{*}{ All Wales fourth } & \multicolumn{3}{|l|}{ City A } & \multicolumn{3}{|l|}{ City B } \\
\hline & $\begin{array}{l}\text { Total road } \\
\text { length }\end{array}$ & $\begin{array}{l}\text { Average } \\
\text { distance } \\
\text { between } \\
\text { features }\end{array}$ & $\begin{array}{l}\text { Traffic calming } \\
\text { density per km } \\
\text { road length }\end{array}$ & $\begin{array}{l}\text { Total road } \\
\text { length }\end{array}$ & $\begin{array}{l}\text { Average } \\
\text { distance } \\
\text { between } \\
\text { features }\end{array}$ & $\begin{array}{l}\text { Traffic calming } \\
\text { density per km } \\
\text { road length }\end{array}$ \\
\hline Most affluent & 240.3 & 3.75 & 0.27 & 249.1 & 3.11 & 0.32 \\
\hline Next affluent & 300.9 & 1.55 & 0.17 & 176.9 & 2.24 & 0.45 \\
\hline Next deprived & 77.3 & 0.81 & 1.84 & 175.6 & 1.38 & 0.72 \\
\hline Most deprived & 114.6 & 0.47 & 5.54 & 197.0 & 0.74 & 1.36 \\
\hline Total & 733.1 & 0.82 & 1.22 & 798.7 & 1.4 & 0.69 \\
\hline
\end{tabular}




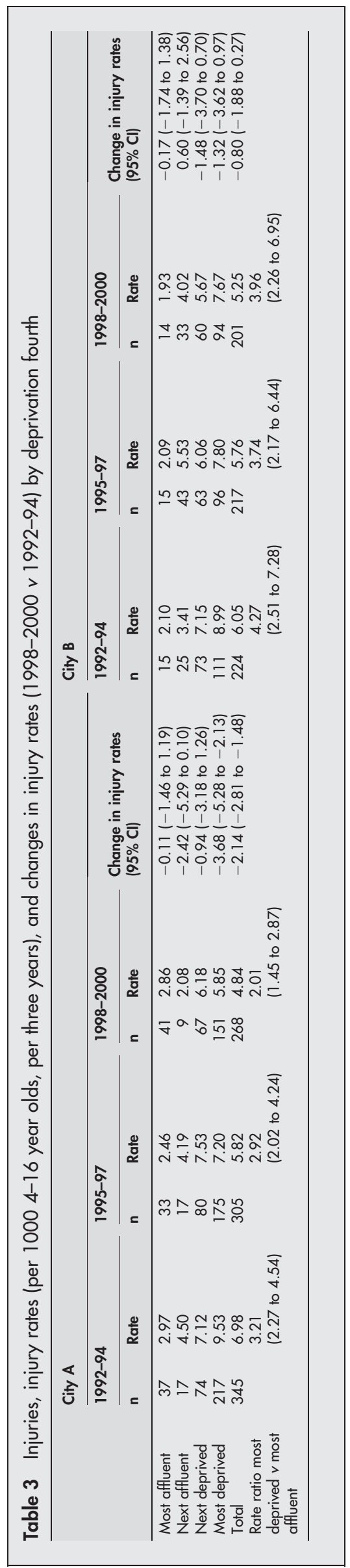

\section{Injury rates}

For 1992-94, child pedestrian injury rates were 6.98 per 1000 4-16 year olds in city A and 6.05 in city B (table 3). By 19982000, city A's injury rate had dropped significantly (decrease 2.14 ), while a non-significant change of 0.8 occurred in city B.

Most deprived injury rates also dropped significantly in city A (table 3); the inequalities gap between the most affluent and most deprived reduced from 3.2 in 1992-94 to 2.0 in 1998-2000. In city B, there were no significant injury rate changes and little change in inequalities.

Changes in injury rates were significantly inversely correlated with density of traffic calming features (number of features per $\mathrm{km}$ road length; $r=-0.769, \mathrm{p}=0.026$; table 2).

\section{School travel}

In city A, $61.5 \%$ of most deprived children walked to school and $64.2 \%$ in city $\mathrm{B}$.

\section{Car ownership}

Between 1991 and 2001 proportions of households without cars dropped from $37.3 \%$ to $29.7 \%$ in city A and from $34.6 \%$ to $28.5 \%$ in city $\mathrm{B}$.

\section{DISCUSSION}

The distribution of traffic calming in two UK cities favours disadvantaged children, although to a much greater extent in city A. If traffic calming reduces pedestrian injuries (the cited literature suggests some doubt), then areas with more calming should see greater reductions in injuries, all else being equal. Our results are compatible with this explanation with greater reductions in deprived areas of city A, where there was more traffic calming, and a significant correlation between change in pedestrian injury rates and density of traffic calming. The phrase "all else being equal" is particularly significant as injury rate changes could be due to measured or unmeasured confounders.

This type of $n=2$ ecological study suffers from lack of power and the potential for bias due to other simultaneous changes in intervention or control areas. However, this study design is almost inevitable in policy evaluation because of difficulties with getting different jurisdictions to randomly allocate policies and laws. Evaluations of many interventions face these difficulties-for example, mandatory use of helmets. Therefore, authors need to consider all possible biases, the extent to which they have or can be measured, and the plausible magnitude and effect of any residual biases on results before accepting that change is due to the intervention.

The main weakness of this study was the lack of traffic calming installation dates. Neither city council held a comprehensive listing of installed features, their locations, and installation dates. Each feature had a design plan, held in hundreds of separate files. Traffic engineers in both cities stated that most features were installed from the mid 1990s onwards. Even if installation dates were available it would not have helped evaluation because features were installed on different roads in individual EDivs over periods of months or years. Evaluating the impact of individual features on child pedestrians is difficult because the number of injuries adjacent to any one structure is often 0 or 1 ; our 1998-2000 injury rate was 0.3 injuries per kilometre.

Other potential biases relate to changing population and environmental exposures between cities, and between deprivation fourths within cities. Population denominators were specific to each time period. Injury rates therefore accounted for population changes. 
Total road length did not differ substantially between cities. Ideally, these calculations would count only roads suitable for traffic calming and along which child pedestrians are exposed, but such decisions are subjective.

Traffic volumes and speeds may have changed during the study period, but there are no suitable data to assess this possibility. National estimates are available but are not appropriate for regional comparisons. Some route analyses have been carried out within each city, but these focus on specific roads for a short period of time-periodic repeat data collection is very unusual.

Exposure to traffic could also have changed or may have varied considerably between the two cities. A National Travel Survey comparing 1989-91 with 1998-2000 found that walking to school by primary school children dropped from $62 \%$ to $56 \%$, and from $48 \%$ to $43 \%$ for secondary school children. $^{21}$ These changes are not sufficient to explain the injury rate changes in city A and should have lead to similar injury rate decreases in both cities. Also, similar proportions of children walked to school in both cities; higher injury rates in city $\mathrm{B}$ are not due to greater exposure. It is possible that there were substantial differences at the beginning of the study period, but discussions with the road safety departments in both cities suggested that no obvious changes had occurred.

When this study began, city A was collecting exposure data for "safe routes to schools" projects which were being implemented in all cities from 2000 onwards; we used an identical form in city B. Data were collected for 9-12 year olds and the sole purpose of collecting these data was to determine whether differences in child pedestrian exposures may explain some of these findings. Analysis of only the 9-12 year age group was considered, but the number of cases $(n=421)$ would have considerably reduced the precision of the point estimates, making definitive conclusions even more difficult. Furthermore, the most appropriate analysis could be argued to include only school journey injuries $(n=265)$. Generalising these data to all 4-16 year olds and all journeys is not ideal and limits these analyses. However, collecting even these data was a substantial task. The alternative would have been to ignore possible variations in exposures and be left with even more unanswered questions. Few road traffic environment studies have adequate exposure data to address all potential confounding.

The limitations of STATS19 have been widely discussed. ${ }^{22-24}$ The main concerns include case ascertainment completeness and accuracy of grid reference reporting. Child pedestrian casualties are underreported in police statistics. ${ }^{24-27}$ Definitions of casualties as fatal, serious, or slight are also known to be problematic. ${ }^{24}{ }^{28}$ For this reason, and because of the small numbers likely in the fatal and serious category, no severity analysis was carried out. More discrepancies are likely when comparing data from different police forces, but both cities are in the same police force area.

Police officers do not carry GPS readers, making inaccuracies in accident location recording possible. In addition, STATS19 is often completed some time after the incident and only records a 10 figure grid reference. Therefore the potential exists for error in accident location recording, but this would be of greater concern with an individual feature based before and after approach. With the fourths ecological approach systematic errors within and between cities are less likely.

STATS19 only records accident location, leading to questions over population denominators. The majority of child pedestrians are injured within $1 \mathrm{~km}$ of their home and the residential population of the area where the accident occurred is therefore an appropriate denominator. ${ }^{27} 2930$ There may be some age related variations in these distances, with older children travelling further than younger children. However, the issue here is not the actual distance travelled,

\section{Key points}

- In a natural experiment traffic calming was concentrated more in deprived areas of one of two cities.

- An ecological analysis of trends in childhood pedestrian injuries shows a substantially greater narrowing of the inequalities gap in the city with the traffic calming concentrated in the deprived areas.

- Examination of potential confounders could not reveal any alternative explanation.

but whether the child crosses an EDiv boundary during the journey, thereby making the residential population an inappropriate denominator. Child pedestrian injuries have previously been shown to cluster around the home and occur in the census tract where the child lives, regardless of age..$^{29} 30$

These findings have been presented to the engineering and road safety departments of both cities. Discussions also took place regarding traffic calming installation and child road safety policies, such as safe routes to school. Some differences in the mechanism for prioritising traffic calming sites were identified, but there were no obvious differences in road safety education that could have changed behaviors and reduced injury risk in city $\mathrm{A}$.

A final issue is whether regression to the mean could explain these changes. This occurs when the group being tested has high values initially, increasing the likelihood that subsequent values will be lower. Since initial injury rates in both cities were similar, it is unlikely that regression towards the mean could explain the differential changes. Regression to the mean may account for changes within each city, changes that we are attributing to traffic calming in city A. However, this argument requires that regression to the mean takes place over a period of nine years. The length of an appropriate period for a regression to the mean consideration is open to debate, as is the point in time at which the mean is calculated.

Drawing definitive conclusions from these analyses is difficult. The ecological approach means that unmeasured factors could have accounted for injury rate changes. However, given the observed changes in inequalities and the analysis of the potential confounders presented here, substantial influence of other variables seems unlikely. Previous research has studied the effectiveness of traffic calming, but none has tried to examine the effects on pedestrian injury inequalities.

Other than a large multisite randomised controlled trial, it is difficult to imagine an evaluation framework which could produce unequivocal results. In the absence of sufficient financial and political support for the large scale and expensive trials there is merit in replicating this study in other areas.

\section{ACKNOWLEDGEMENTS}

Thanks to road safety engineers in both cities for general advice and to Sylvie Morgan, Linda Jones, Brian Jones, and Luke Jones for assistance with surveying.

\section{Authors' affiliations}

S J Jones, S R Palmer, Department of Epidemiology Statistics and Public Health, Cardiff University, Cardiff, UK

R A Lyons, Centre for Health Improvement Research and Evaluation University of Wales Swansea, Swansea, UK

A John, National Public Health Service for Wales Swansea Office, Swansea UK

This research was partly funded by a grant from the Chief Medical Officer for Wales. 


\section{REFERENCES}

1 Murray C, Lopez A. The global burden of disease. Cambridge, MA: Harvard University Press, 1996.

2 Krug E. Injury A leading cause of the global burden of disease. Geneva: World Health Organization, 1999.

3 Rivara FP. Child pedestrian injuries in the United States. Am J Dis Child 1990; 144:692-6.

4 UNICEF. A league table of child deaths by injury in rich nations, Innocenti Report Card No 2, February 2001. UNICEF, Florence: Innocenti Research Centre.

5 Roberts I. Safely to school. Lancet 1996;347:1642.

6 Christie N. Social, economic and environmental factors in child pedestrian accidents: A research review. Project report 116. Crowthorne: Transport Research Laboratory, 1995.

7 Avery JG, Jackson RH. Children and their accidents. Sevenoaks: Edward Arnold, 1993.

8 Lyons RA, Jones SJ, Deacon T, et al. Socioeconomic variations in injury in children and older people: population based study. Inj Prev 2003;9:33-7.

9 Milward L, Kelly M, Nutbeam D. Public health intervention research: the evidence. London: Health Development Agency, 2001

10 Towner E, Dowswell T, Mackereth $\mathrm{C}$, et al. What works in preventing unintentional injuries in children and young adolescents. London: Health Education Authority, 2001

11 Webster D, Mackie A. Review of traffic calming schemes in $20 \mathrm{mph}$ zones, TR Report 215. Crowthorne: TRL, 1996.

12 Engel U. Seminar on short term and area wide evaluation of safety measures. 1982:251-9.

13 Bunn F, Collier T, Frost C, et al. Area wide traffic calming for preventing traffic related injuries (Cochrane Review). In:The Cochrane Library, Issue 1, 2003, edn. Oxford.

14 ArcView. Environmental Systems Research Institute, 1992-1999.

15 PAT18. Working paper: Measuring deprivation-A review of indices in common use, Available at www.cabinet-office.gov.uk/sED/2000/pat18/ Depindices.htm (accessed 12 April 2005)
16 UK Data Archive. Available at http://www.data-archive.ac.uk/ laccessed 12 April 2005).

17 RoSPA. Road safety engineering manual. London: RoSPA, 2002

18 Newcombe RG. Confidence limits for the ratio of two rates based on likelihood scores: non-iterative method. Stat Med 2003;22:2085-6.

19 Newcombe RG. Two-sided confidence intervals for the single proportion: comparison of seven methods. Stat Med 1998;17:857-72.

20 Ordnance Survey. Meridian 2. Southampton: Ordnance Survey, 2003.

21 DfT. Focus on personal travel, Department for Transport, Local Government and the Regions, 2001.Available at http://www.dft.gov.uk/stellent/groups/ dft_transstats/documents/page/dff_transstats_505809.pdf (accessed 12 April 2005).

22 Maas MW, Harris S. Police recording of road accident in-patients. Accid Anal Prev 1984;16:167-84.

23 Edwards JB. Road accident data: sources, selection and justification, Transport Research Group Working Paper, No 5. Department of Maritime Studies and International Transport. Cardiff: University of Wales College Cardiff, 1992.

24 Henson R, Hadfield J, Cooper S. Injury control strategies: extending the quality and quantity of data relating to road traffic accidents in children. Emerg Med J 1999;16:87-90.

25 RAGB. Road accidents Great Britain. London: HMSO, 1992.

26 Tunbridge RJ, Everest JT, Wild BR, et al. An in-depth study of road accident casualties and their injury patterns, TRRL report RR136-7. Crowthorne: TRL, 1988.

27 Ward H, Cave J, Morrison A et al. Pedestrian activity and accident risk Basingstoke: AA Foundation for Road Safety Research, 1994.

28 James HF. Under reporting of road traffic accidents. Traffic Engineering and Control 1991;32:574-80

29 Abdalla I, Raeside R, Barker D, et al. An investigation into the relationship between area social characteristics and road accident casualties. Accid Anal Prev 1997;29:583-93.

30 Joly MF, Foggin PM, Pless IB. Geographical and socio-ecological variations of traffic accidents among children. Soc Sci Med 1991;33:765-9.

\section{LACUNAE}

\section{First step toward mandatory US standard for cigarefte lighters}

T

he US Consumer Product Safety Commission (CPSC) has voted unanimously to move forward with the first of three steps in developing a new mandatory safety standard for

cigarette lighters. The vote to approve an Advanced Notice of Proposed Rulemaking sets the Commission on a path to consider a way to prevent most mechanical malfunctions of lighters and reduce the fire hazard associated with some lighters. CPSC already has a mandatory standard for child-resistant cigarette lighters which addresses the hazard of children under 5 years starting fires with lighters. That standard for child-resistance applies to imported as well as domestically-manufactured disposable and novelty lighters. There are nearly one billion cigarette lighters sold in the US annually. Over 700 million lighters are imported each year, with about 400 million coming from China. From 1997 to 2002, the CPSC estimated that more than 3000 people went to hospital emergency rooms for injuries resulting from malfunctioning lighters. Most of these injuries involved thermal burns to the face, hands, and fingers. The voluntary standard for lighters addresses the risk of fire, death, and injury associated with mechanical malfunctions of lighters. However, it is unclear how many lighters sold in the US actually comply with the voluntary standard. Fire deaths associated with children playing with lighters dropped dramatically since the mandatory standard for child-resistance became effective in July 1994-from 230 in 1994 to 130 in 1998. Children under 5 years accounted for 170 of the deaths in 1994 and 40 of the deaths in 1998. In 1994 there were 11100 residential fires associated with children playing with lighters. By 1998, that number declined to 6100 fires. 